\title{
O USO DE EDIFICAÇÕES HISTÓRICAS PARA O ENSINO DE ESTRUTURAS
}

Gabriel H. S. Yagnycz'; Gabriel P. Ferreira'; Lorena B. S. Clavijo'; Murilo F. Primo $^{1}$, Náthali B. Giacomini ${ }^{1}$; Nathany C. Oliveira ${ }^{1}$; Elvidio Gavassoni².

${ }^{1}$ Discente do curso de Engenharia Civil da Universidade Federal do Paraná

2 Docente do Departamento de Construção Civil da Universidade Federal do Paraná

PET Engenharia Civil, Universidade Federal do Paraná, Curitiba, Paraná.

Palavras-chave: Ensino; Análise Estrutural; Estruturas Históricas.

\section{Introdução}

Segundo o Manual de Orientações Básicas do Programa de Educação Tutorial, "um grupo tutorial se caracteriza pela presença de um tutor com a missão de estimular a aprendizagem ativa dos seus membros, através de vivência, reflexões e discussões, num clima de informalidade e cooperação". O PET Engenharia Civil UFPR, realiza desde 2013 o projeto chamado "Treinamento com o Tutor" como forma de fortalecer e consolidar o caráter tutorial do grupo.

O projeto consiste de um curso ministrado semestralmente por nosso tutor tendo por base um assunto escolhido pelo grupo dentre uma lista sugerida pelo tutor, pertinente às suas atividades técnicas, sendo estes assuntos pouco ou não tratados na graduação. O conteúdo é passado aos alunos através de aulas expositivas e ferramentas ativas preparadas previamente pelo professor. Os treinamentos visam a transmissão de conhecimento profissional, científico e didático aos integrantes para complementar sua formação acadêmica, sempre através de metodologias inovadoras e distintas das aplicadas em sala de aula.

No primeiro semestre do ano de 2018, participamos do treinamento a respeito de Estruturas Históricas com enfoque nas Igrejas Góticas, no qual tivemos a oportunidade de aprender sobre o funcionamento estrutural de obras góticas e seus elementos característicos, além de seu enorme significado histórico e 
arquitetônico. Tais tópicos foram abordados ao longo do treinamento por meio de metodologias inovadoras e ativas, com aplicação prática de conhecimento adquirido na teoria, como será explicado em seguida.

\section{Metodologia}

Antecedeu ao treinamento em Estruturas Históricas, os treinamentos básicos de nivelamento em Mecânica Estrutural e elementos de Arquitetura Gótica. A primeira aula foi sobre conceitos básicos de Resistência dos Materiais, ministrada por um dos petianos do $3^{\circ}$ ano do curso. Posteriormente, a aula sobre Arquitetura Gótica com o arquiteto Thiago Plaça Teixeira.

A parte de nivelamento ministrada por um petiano foi bastante importante, já que o grupo que participou do treinamento era composto por alunos do $1^{\circ}$ ao $3^{\circ}$ ano e nem todos possuíam os conhecimentos básicos necessários para entendimento pleno do curso. A apresentação durou cerca de uma hora e foram abordados conceitos de Resistência dos Materiais, matéria que faz parte do $2^{\circ}$ ano do curso de Engenharia Civil na UFPR.

Foram explicados os termos físicos básicos força, compressão, tração e atrito e os de propriedades mecânicas dos materiais estruturais tensão, flexão, tipos de deformações e fragilidade. Isso foi feito através da explanação do conceito teórico, uso de imagens ilustrativas e, também, de dispositivos didáticos simples, mas que facilitam o entendimento dos conceitos, especificamente uma esponja para demonstrar compressão e um pedaço de plástico de embalagens e um elástico de dinheiro para exemplificar deformação e fragilidade.

Para abordar a parte de arquitetura histórica foi feita uma aula específica com um especialista da área que durou cerca de uma hora e meia. O curso começou com a definição dos três principais conceitos da arquitetura: Firmitas, parte construtiva, Utilitas, parte funcional, e Venustas, parte estética. Então, foi explicado como é feita a titulação das igrejas católicas e, utilizando uma Basílica Cristã como exemplo, foram explanadas as principais partes de uma igreja, que podem ser observadas na figura 1. 
Figura 1: Partes da Catedral Basílica Menor de Nossa Senhora da Luz dos Pinhais

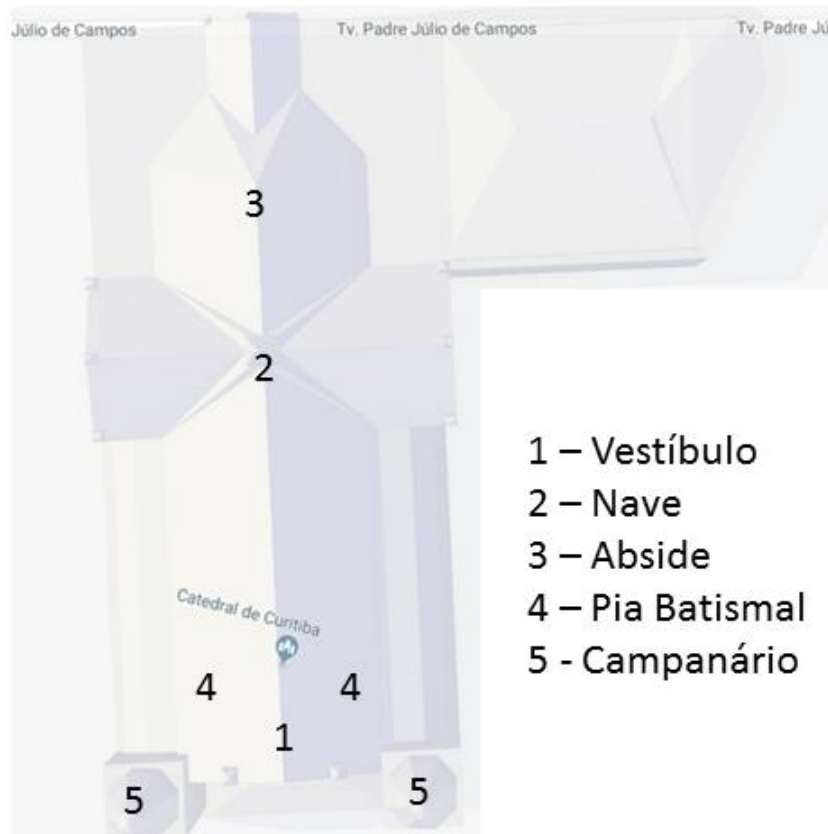

Fonte: AUTORES, 2018.

Após a introdução, foram apresentadas as principais diferenças entre a arquitetura Gótica e a Românica. Esta utiliza as paredes como elemento estrutural, não possuindo grandes portas e janelas. Enquanto aquela possui projeto estrutural e a alvenaria somente de vedação; além disso, ela segue diversos padrões, como a utilização de arcos e abóbadas ogivais, busca sempre a valorização da geometria, mantendo sua proporção, e procura ter construções extremamente altas e muito bem iluminadas através dos vitrais, remetendo ao aspecto ideológico de visão divina.

O treinamento com o tutor, propriamente dito, ocorreu em dois dias, com duração total de 3 horas. Nele, o tutor, Prof. Dr. Elvidio Gavassoni, explicou o funcionamento das estruturas de elementos básicos da arquitetura gótica: domos, arcos, abóbadas, arco-botantes, contraforte, pináculos, flechas e coruchéus. Para ilustrar o funcionamento da compressão que os arcos sofrem, o tutor fez a analogia com cabos, pois da mesma forma que cabos funcionam somente a tração, os arcos trabalham somente a compressão. Da mesma maneira, o tutor utilizou de cascas de frutas, como maracujá e tangerina, cortadas ao meio e sem a polpa, para ilustrar o funcionamento das estruturas e a estabilidade dos arcos e domos. Um conjunto de cascas, canivete e tábua de 
cortar foi entregue a cada grupo de 3 petianos discentes que estava participando no treinamento, e com isso os alunos podiam cortar pedaços das cascas e visualizar como isso afetava as estruturas.

Ao longo do treinamento, o tutor foi apresentando exemplos e fotos de igrejas góticas que continham os elementos supracitados, além de explicar o fluxo das tensões e as fórmulas utilizadas para calcular, por exemplo, a altura máxima que uma torre poderia ter, dado o peso específico, o diâmetro da torre e a força do vento. Também mostrou a forte relação que as estruturas tinham com a arquitetura naquela época e que os métodos utilizados para garantir o equilíbrio dessas estruturas eram majoritariamente empíricos.

Figura 2: Dia do Treinamento com o Tutor

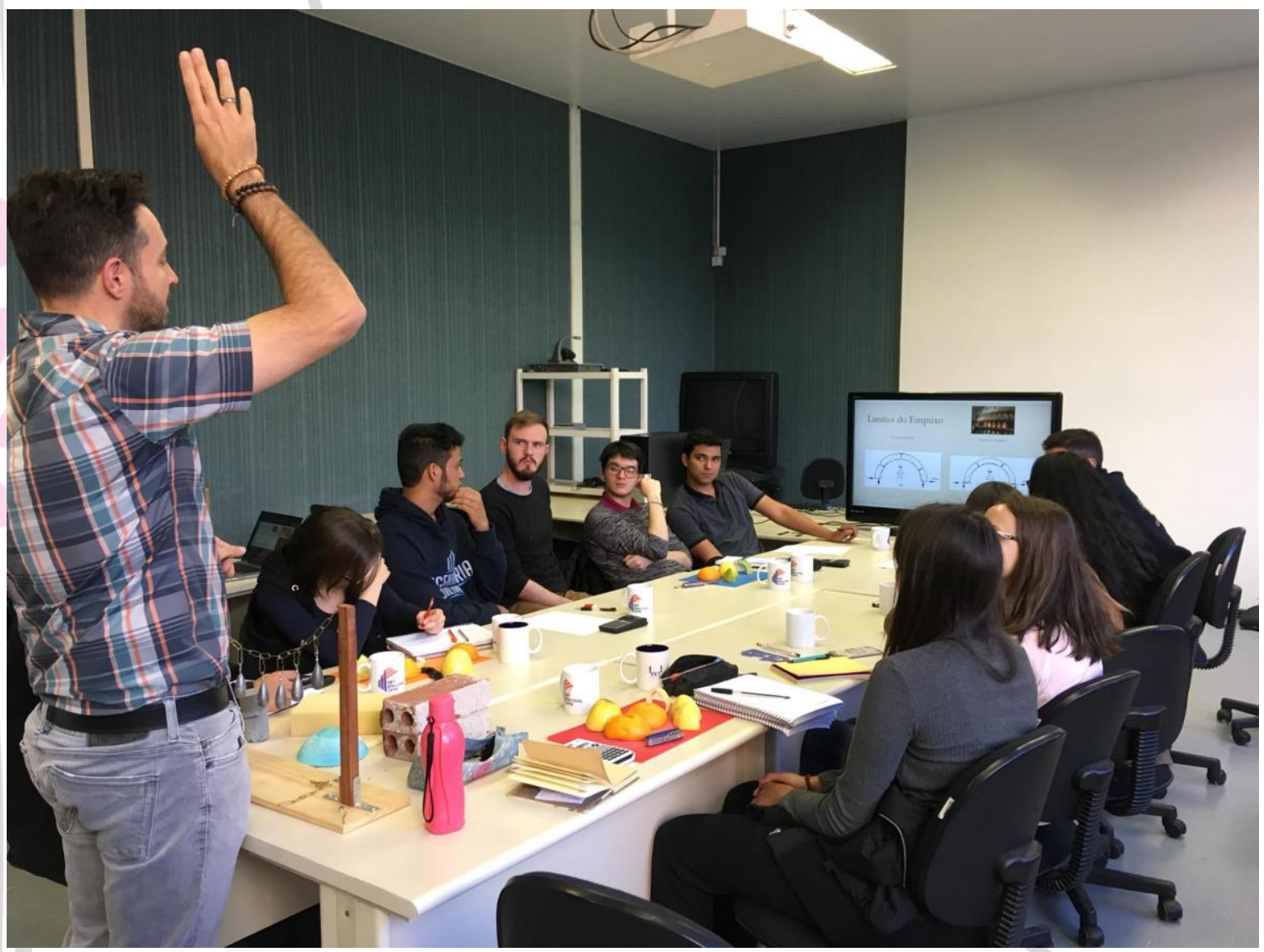

Fonte: AUTORES, 2018.

Após o curso ser finalizado, foi realizada uma visita técnica à Catedral Basílica Menor de Nossa Senhora da Luz dos Pinhais, localizada em Curitiba-PR. A visita durou 3 horas e foi guiada pelo professor tutor e pelo arquiteto Thiago; nela, foi analisada a construção tanto pelo viés arquitetônico, quanto pelo 
estrutural. Na catedral foi possível observar de perto os elementos estudados nos treinamentos anteriores. No local, o professor tutor desenvolveu cálculos simples com o auxílio de uma ficha de campo com croquis e medições para que os discentes tivessem a experiência de um engenheiro estrutural.

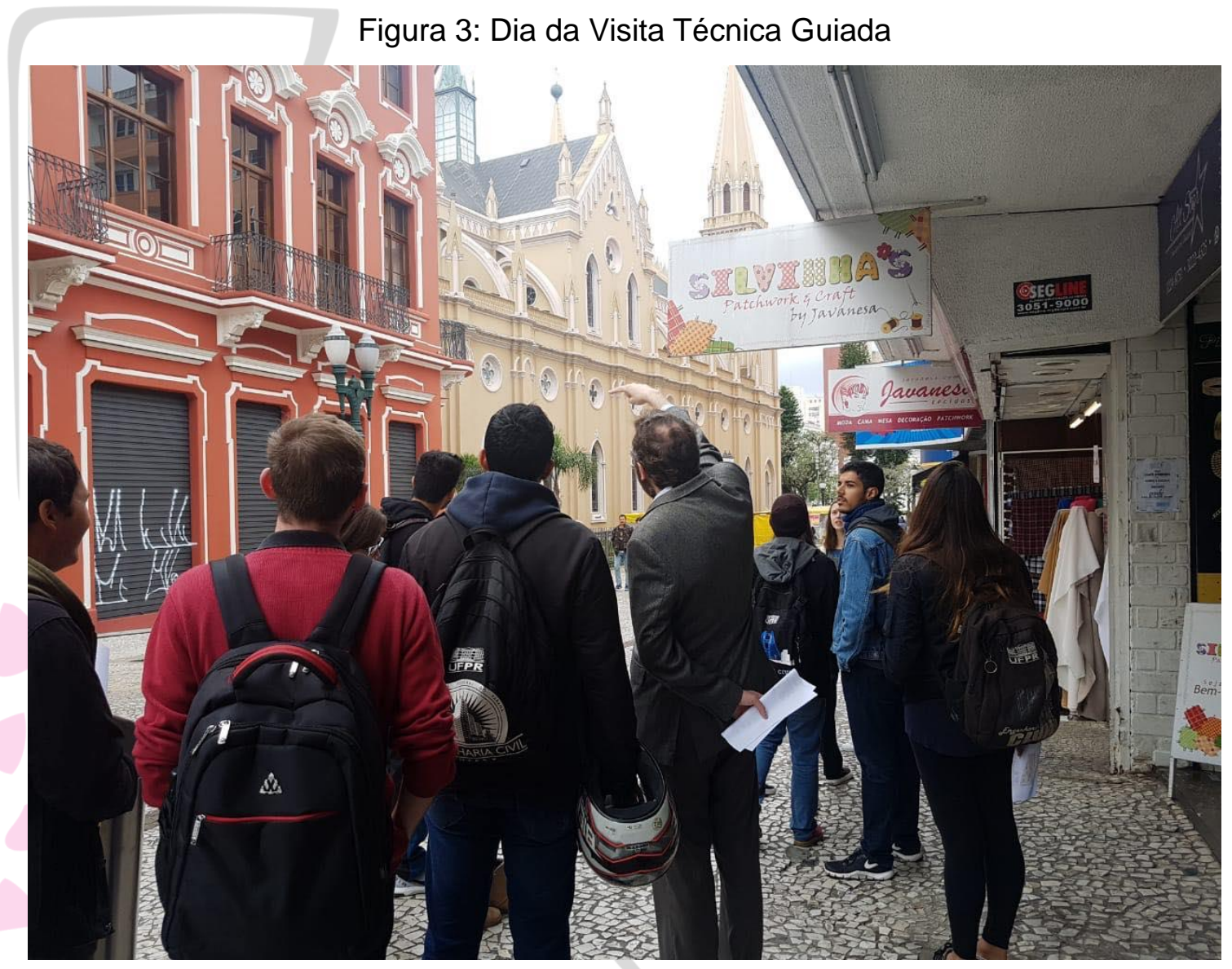

Fonte: AUTORES, 2018.

\section{Resultados e discussão}

Os resultados provenientes deste treinamento foram vários, tanto 0 conhecimento adquirido sobre o comportamento estrutural até o contexto histórico sobre o desenvolvimento e evolução das estruturas góticas e como elas ainda estão presentes e fortes no dia-a-dia. O nivelamento que aconteceu com o arquiteto no início do curso, foi de grande valia para ser entendido como foram pensados aqueles formatos para as estruturas, além de ter a percepção da importância da estética das igrejas para a época e também como patrimônio cultural atualmente. 
Para o estudo estrutural, o grupo percebeu muitas aplicações do conhecimento teórico previamente tido em sala de aula, principalmente na disciplina de Resistência de Materiais. Esses conhecimentos prévios foram necessários para o dia da visita, em que fizemos a análise do comportamento e caminho que os esforços seguem nas estruturas da Catedral de Curitiba. Essa ficha foi como um teste, para comprovar o quanto de conhecimento foi absorvido durante todo o treinamento.

Ademais, houve discussões para ampliar o curso para toda a graduação, fazendo uma segunda edição, mas desta vez com a participação ativa de todos os petianos, partindo-se do pressuposto de que todos já haviam participado como ouvintes, agora seriam ativos para a execução do treinamento. Infelizmente não aconteceu devido ao tempo que o projeto demandaria, o que não estava previsto no planejamento.

\section{Conclusões}

O curso de Estruturas Históricas foi efetivo, visto que atingiu o objetivo de aprendizado com a tutoria e aproximação do professor. Além disso, o atingimento do curso foi positivo, já que dele os petianos discentes adquiriram conhecimento técnico: da parte estrutural ministrada pelo PETiano discente Vinicius Eduardo Leopoldino Rupel e pelo professor tutor Elvidio Gavassoni Neto, e histórico das estruturas com o arquiteto Thiago Plaça Teixeira; foi submetido o projeto Treinamento com o Tutor - com enfoque no curso de Estruturas Históricas - no XXIII ENAPET e foi idealizada a expansão do curso, agora ministradas pelos próprios PETianos para a graduação.

\section{Referências}

HIBBELER, R. C. Resistência dos Materiais. 7aㅡ Edição. São Paulo: Pearson Prentice Hall, 2010.

GAVASSONI, Elvidio. O aprendizado e o Ensino da Análise Estrutural. Disponível em: <http://petcivil.blogspot.com/2018/11/o-aprendizado-e-o-ensinoda-analise.html> Acesso em: 25 de novembro de 2018. 